\title{
ASYMPTOMATIC DIAPHRAGMATIC DEFECT - A POST-OPERATIVE PROBLEM
}

\author{
M. KeERI-SZanto
}

DISPLACEMENT of the thoracic contents by intraperitoneal structures is a well-known serious complication in traumatology and neonatology' but is not usually included in the differential diagnosis of cardiorespiratory problems facing the anaesthetist under other circumstances. We wish to report here on such a complication seen after non-emergent surgery in an adult, carried out on a site remote from the chest and to comment on the ventilatory and metabolic requirements during early recovery from anaesthesia and operation.

\section{CASE REPORT}

A woman 50 years of age sought help for intractable facial pain of some months' duration. Investigation revealed a malignancy of the left maxillary antrum which was first treated by radiotherapy. This relieved the pain but the sessions produced severe bouts of gagging and retching. The Anaesthesia Service forst met the patient during the initial admission three months earlier, when she was anaesthetized uneventfully for a Caldwell-Luc procedure lasting 75 minutes. She was now seen on the eve of a proposed radical left maxillectomy with possible exenteration of the orbit. Functional inquiry revealed a Para II Gravida II mildly apprehensive lady who claimed to be in robust health in spite of her small size $(42.5 \mathrm{~kg})$ with no recent weight loss. Blood chemistry and other laboratory findings were in the normal range.

Following intravenous hyperalimentation for the eight hours preceding operation ${ }^{2}$ and routine premedication, anaesthesia was induced with intravenous hydromorphone and the exhibition of 70 per cent nitrous oxide with oxygen. ${ }^{3}$ During most of the induction the patient was breathing spontaneously. Controlled ventilation by mask was utilized for less than one minute after the injection of succinylcholine $50 \mathrm{mg}$ in preparation for nasotracheal intubation which was carried out without mishap. She was then connected to a respirator through a Bain-Tube ${ }^{4}$ and was venti-

M. Keeri-Szanto, M.D., F.R.C.P.(C), Department of Anaesthesia, Victoria Hospital, London, Ontario, N6A 4G5.

Canad. Anaesth. Soc. J., vol. 25, no. 2, March 1978 lated in an isocapnoeic fashion ${ }^{5}$ using a fresh gas inflow of $3.1 \mathrm{l} / \mathrm{sq} \mathrm{m} / \mathrm{min}$. Air entry to both apices was checked before draping and was found to be free and equal. Planned hypotension to the level of approximately 60 per cent of the resting systolic blood pressure was provided for about 50 minutes, using a slow drip of trimetaphan. Monitoring consisted of the display of peripheral pulse waves, mixed exhaled $\mathrm{PCO}_{2}{ }^{6}$ and rectal temperature as well as frequent blood pressure readings through a Doppler apparatus. By these criteria the patient's course was entirely uneventful and the operation was completed in three hours with an estimated blood loss of $750 \mathrm{ml}$, the orbital exenteration being unnecessary. One unit of blood was given in the operating room. The patient's $\dot{\mathrm{V}} \mathrm{CO}_{2}$ was in the range of 120 per cent of predicted except for the final 45 minutes, when it rose to 145 per cent. Rectal temperature dropped as low as $35.9^{\circ} \mathrm{C}$ and was rising again by the end of the operation. The patient reached the Intensive Care Unit with the nasotracheal tube in place, rousing and shivering. She was connected to a Bird ventilat or that she triggered regularly, moving approximately eight litres of oxygenenriched air per minute. It was planned to keep the tube in place for 12 to 24 hours to protect the airway against swelling of the pharyngeal wall. A routine antero-posteror-chest film was taken to document its position in the trachea.

As the patient's consciousness cleared, the shivering became more marked and signs of air hunger developed, even though the ventilator appeared to work well and large volumes of gas were moved. Air entry to the left hemithorax diminished. The cuff was deflated and reinflated several times and patency of the tracheal tube was demonstrated by the easy passage of a suction catheter. Some delay was experienced in receiving the post-operative chest film (Figure 2). As soon as the film was seen, we switched the patient to 100 per cent oxygen and reviewed her earlier chest films. A definite diaphragmatic defect was evident on a film taken three months earlier, before the start of radiotherapy and the first anaesthetic. This had increased about threefold in size on the chest plate taken during the 


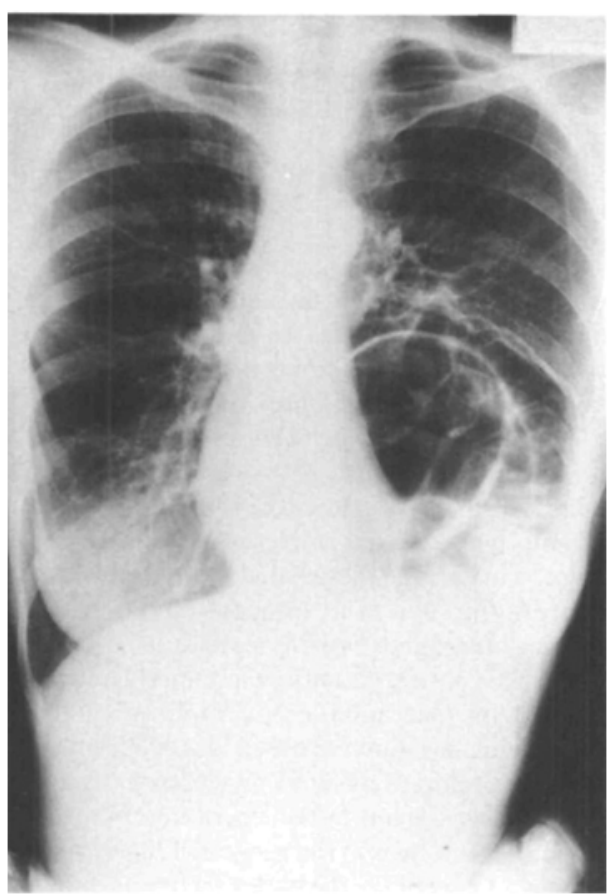

Figure I Admission PA chest film (erect). Stomach and large bowel rise to the seventh posterior space, mild mediastinal shift. There are lung markings in the (L) costophrenic angle.

present admission (Figure 1) that was not yet reported back at the time. A gastric tube was passed with great care through the mouth and large amounts of gas along with about $250 \mathrm{ml}$ of blood were aspirated. This immediately relieved her air hunger. She went to sleep and was reading the paper in bed before the nasotracheal tube was removed. Her further recovery was uneventful despite the persisting grossly abnormal radiological findings in her thorax (Figure 3). Insistent questioning about symptoms that could be referred to a diaphragmatic hernia or events that would explain the origin of such a lesion remained fruitless. It is planned to watch her closely for any clinical sign of the hernia and to undertake its surgical correction only if the complaints warrant it.

\section{Discussion}

Gastric inflation during the induction of anaesthesia is a common mishap and intragastric pressures equalling and even exceeding the bag pressure have been reported. The short period of positive pressure ventilation by mask in this case argues against this possibility although it cannot be completely excluded. An alternative explanation is also well known; if there is an air bubble present in a well-perfused organ and the composition of inhaled gases is switched from air (oxygen-nitrogen) to oxygen-nitrous oxide, the different solubilities of nitrogen and nitrous oxide will soon lead to a four-fold increase of the pressure-volume product. The presence of such a bubble in this patient is documented in Figure 1. Once the nitrous oxide is discontinued, the gas should disappear from the bubble as rapidly as it diffused in, unless the expansion of the organ interfered with the blood flow through the wall, in which case the return to pre-anaesthetic conditions might be quite prolonged. This is what probably happened to our patient.

The true incidence of diaphragmatic hernia is much greater than the incidence of its diagnosis would suggest. ${ }^{7.8}$ The present case furnishes one explanation for this anomaly. The pre-operative $\mathrm{X}$-ray suggests a progression of the lesion. In addition, during the operation the left lung was almost completely compressed and even the right lung function was jeopardized. Yet the patient

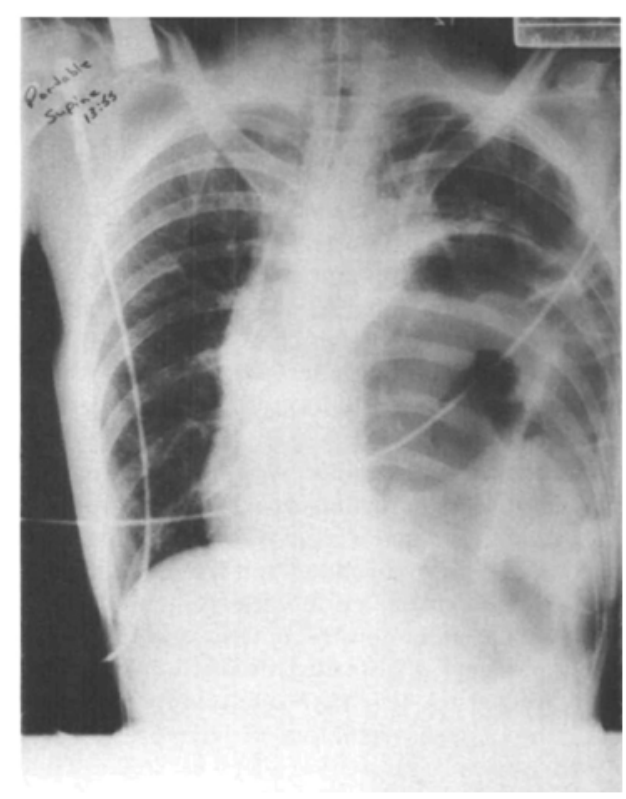

FIGURE 2 Supine AP chest film one hour after end of surgery. ET tube in place. Abdominal contents elevated to the fourth posterior intercostal space, no lateral lung markings below that level. Substantial mediastinal shift. Patient shivering, complains of air hunger. 




Figure 3 Supine AP chest film 18 hours later. ET and gastric tubes in place. Large bowel shadow in chest, lateral lung markings returned. Patient completely asymptonatic.

remained asymptomatic despite a metabolic activity greater than predicted for her resting state. Only when the metabolic demands increased further (during shivering) did signs of air hunger appear. It would seem that external compression of the left lung amounted to a functional pneumonectomy that did not interfere with the ventilation/perfusion relationship but limited her exercise tolerance, as it were. The argument is reinforced by the fact that marked residual pathology on X-ray (Figure 3) did not affect the favourable clinical course of this patient once the increased metabolic requirements subsided.

It is all too often disregarded in the early postoperative management of patients that, even though they might be lying quietly in bed, they are far from resting. They might in fact be working desperately hard simply to stay alive. We have long advocated that patients who might not tolerate such a level of metabolic demand should be identified ahead of time and supported postoperatively by assisted ventilation, ample supply of metabolic substrates and judicious sedation that will spread the metabolic demands over a longer period of time. ${ }^{9}$ The present case is simply an extreme example of this proposition.
SUMMARY

A three-hour operation on the maxilla of a woman with an unrecognized large left diaphragmatic defect using narcotic-supplehented nitrous oxide anaesthesia resulted in nearcomplete compression of her left lung. The condition remained asymptomatic until post-operative shivering increased the patient's metabolic requirements, leading to signs of air hunger. Aspiration of large amounts of gas from the stomach promptly relieved all symptoms in spite of significant residual $\mathrm{X}$-ray findings.

It is important to keep in mind that the early post-operative period is usually one of intense metabolic activity rather than of rest. Patients who are unlikely to cope with such demand should be identified pre-operatively and supported prophylactically by ventilatory assistance, ample supply of metabolic substrates and judicious sedation.

\section{RÉSUMÉ}

Une hernie diaphragmatique, importante mais insoupçonnée, conduisait à un collapsus presque complet du poumon gauche, à la suite d'une chirurgie maxillaire d'une durée de trois heures effectuée sous anesthésie générale (NarcotiqueProtoxyde d'azote). Cette condition ne se manifesta qu'à la phase d'émergence post-opératoire alors qu'un frisson augmenta les besoins métaboliques avec signes de détresse respiratoire. L'aspiration d'une grande quantité de gaz de l'estomac mit rapidement fin aux symptômes bien qu'il $y$ eût persistance de signes radiologiques significatifs.

Il est important de se rappeler que la période post-opératoire immédiate en est une d'activité métabolique intense plutôt que de repos. Les patients incapables de faire face à des demandes accrues devraient être identifiés au préalable et devraient bénéficier d'un support respiratoire, de substrats métaboliques adéquats et d'une sédation judicieuse.

\section{ACKNOWLEDGEMENTS}

Dr. H. Heeneman and Dr. M.S. Lefcoe's contributions in referring this case and in assisting with the initial radiological consultation and the review of the illustrations in this report respectively are gratefully acknowledged. 


\section{REFERENCES}

1. Loвb, T.R. \& Butl.in, G.R. Anaesthesia and fraumatic diaphragmatic hernia. Canad. Anaes. Soc. J. 21: 173 (1974).

2. KeERI-Szanto, M. Thermometry during surgery: an index of metabolic competence. Presented at the C.A.S. Annual Meeting, Kingston, Ontario, June 1975.

3. KEERI-Szanto, M. Anaesthesia time/dose curves IX: the use of hydromorphone in surgical anaesthesia and post-operative pain relief in comparison to morphine. Canad. Anaes. Soc. J. 23: 587 (1976).

4. Bain, J.A. \& Spoerel, W.E. Flow requirements for a modified Mapleson D System during controlled ventilation. Canad. Anaes. Soc. J. 20: 629 (1973).
5. KeER1-Szanto, M. Isokapnic ventilation during surgical operations: description of equipment and first resuits. Anes. \& Analg. 49: 406 (1970).

6. Greenway, R.E., Heeneman, H., \& KeerlSzanTo, M. Circulatory monitoring using a carbon dioxide analyzer during planned hypotension: a clinical note. Canad. Anaes. Soc. J. $24: 282$ (1977).

7. SuTherLaNd, W.H. Diaphragmatic hernia in: gastroenterology. McGraw-Hill Book Company, New York, A. Bogoch, Editor. Pp. 250-279 (1973).

8. Bailey and Love's short practice of surgery. H.K. Lewis \& Co., London, pp. 682-684, 14th ed (1968).

9. Aubry, U., Denis, R., Keeri-Szanto, M. \& PaRENT, M. Factors affecting survival of the geriatric patient after major surgery. Canad. Anaes. Soc. J. $12: 510(1965)$ 